\section{OPEN ACCESS}

Edited by:

Jose A. Garcia-Sanz,

Spanish National Research Council

(CSIC), Spain

Reviewed by:

Tomohiro Chiba,

Kyorin University School of

Medicine, Japan

Fabiana Napolitano,

University of Naples Federico II, Italy

${ }^{*}$ Correspondence

Gabriela Coeli Menezes Evangelista gabrielacmevangelista@gmail.com

Maria Alejandra Clavijo-Salomon

mariasalomon@usp.br

†These authors have contributed equally to this work

¥These authors have contributed equally to this work and share senior authorship

Specialty section: This article was submitted to

Women's Cancer,

a section of the journal

Frontiers in Oncology

Received: 02 April 2019

Accepted: 11 July 2019

Published: 20 September 2019

Citation:

Evangelista GCM, Salvador PA,

Soares SMA, Barros LRC

Xavier FHdC, Abdo LM,

Gualberto ACM, Macedo GC Clavijo-Salomon MA and Gameiro J

(2019) 4T1 Mammary Carcinoma Colonization of Metastatic Niches is

Accelerated by Obesity.

Front. Oncol. 9:685.

doi: 10.3389/fonc.2019.00685

\title{
4T1 Mammary Carcinoma Colonization of Metastatic Niches Is Accelerated by Obesity
}

\begin{abstract}
Gabriela Coeli Menezes Evangelista ${ }^{1,2 * \dagger}$, Pollyanna Amaral Salvador ${ }^{1 \dagger}$, Sara Malaguti Andrade Soares ${ }^{1}$, Luciana Rodrigues Carvalho Barros ${ }^{3}$, Felipe Henrique da Cunha Xavier', Luiza Macedo Abdo ${ }^{1}$, Ana Cristina Moura Gualberto ${ }^{1}$, Gilson Costa Macedo ${ }^{1}$, Maria Alejandra Clavijo-Salomon ${ }^{2,3 *}$ and Jacy Gameiro ${ }^{1 \neq}$

${ }^{1}$ Laboratory of Immunology of Infectious and Parasitic Diseases and Obesity, Department of Parasitology, Microbiology, and Immunology, Federal University of Juiz de Fora, Juiz de Fora, Brazil, ${ }^{2}$ Laboratory of Tumor Immunology, Department of Immunology, Institute of Biomedical Sciences, University of São Paulo, São Paulo, Brazil, ${ }^{3}$ Center of Translational Research in Oncology, Institute of Cancer of São Paulo, ICESP, University of São Paulo Medical School, São Paulo, Brazil
\end{abstract}

Breast cancer $(\mathrm{BC})$ remains the leading cause of cancer-related deaths among women, and the chances to develop it are duplicated by obesity. Still, the impact of obesity during $\mathrm{BC}$ progression remains less understood. We investigated the role of obesity in tumor progression using the murine model of $4 \mathrm{~T} 1$ mammary carcinoma in BALB/C female mice, previously high-fat-diet (HFD) fed. HFD induced obesity, metabolic impairment, and high serum and fat leptin levels. After injection of 4T1-cells, HFD-mice accelerated tumor progression and metastasis. 4T1-cells found within HFD-mice metastatic niches presented higher clonogenic potential. 4T1-cells treated in vitro with fat-conditioned medium derived from HFD-mice, increased migration capacity through CXCL12 and CCL25 gradients. In HFD-mice, the infiltration and activation of immune cells into tumor-sentinel lymph nodes was overall reduced, except for activated $\mathrm{CD}^{+}{ }^{+} \mathrm{T}$ cells expressing low CD25 levels. Within the bone marrow, the levels of haematopoiesis-related IL-6 and TNF- $\alpha$ decreased after 4T1-cells injection in HFD-mice whereas increased in the controls, suggesting that upregulation of both cytokines, regardless of the tumor, is disrupted by obesity. Finally, the expression of genes for leptin, CXCR4, and CCR9 (receptors of CXCL12 and CCL25, respectively) was negatively correlated with the infiltration of CD8T cells in human triple-negative BC tumors from obese patients compared to non-obese. Together, our data present early evidence of systemic networks triggered by obesity that promote BC progression to the metastatic niches. Targeting these pathways might be useful to prevent the rapid BC progression observed among obese patients.

Keywords: obesity, breast cancer, 4T1 cells, high fat diet, immune-cells infiltration 


\section{INTRODUCTION}

Obesity has become a public health concern worldwide. According to data from the WHO, $13 \%$ of the world's adult population was considered obese in 2016 (1). Cancer is the second leading cause of death worldwide, accountable for 8.8 million deaths in 2015 (2). Among all tumors that affect women, $25.2 \%$ correspond to breast cancer, which is the world's leading cause of women's death (3). As stated by the International Agency for Research on Cancer-IARC, more than 13 different types of cancer are directly correlated with excess weight or obesity, whereas these conditions are associated with higher risk and lower survival rates in other cancer types (4). Within breast cancer (BC), obesity has been associated with higher morbidity; women who gained between 0.5 and $2 \mathrm{~kg} / \mathrm{m}^{2}$ after having a breast tumor diagnosed had an elevated risk of death compared with women who maintained their weight (5).

The connection between obesity and breast cancer is, in part given to low-grade chronic systemic inflammation initiated by the accumulation of fat, which attracts inflammatory cells that secrete cytokines, chemokines, and growth factors with protumorigenic potential (6). Though the exact mechanisms that link obesity to breast cancer are not yet fully understood, obesity is known to impair sexual hormones, such as fat tissue-produced oestrogen which is directly linked to the development of breast malignancies (7). Additionally, metabolic changes caused by obesity alter critical hematopoietic and immunologic pathways, such as TNF- $\alpha$, IL-1, IL-6, and $\mathrm{PGE}_{2}$, which also have protumorigenic potential $(6,8)$.

To better understand obesity, different animal models have been developed (9). Diet-induced obesity is the scenario that most accurately represents the process in humans, as it increases the intake of lipids and/or sugars (such as in western diets), causing energy imbalance between calories consumed and calories burned (10). As a breast cancer model, primary tumor cells taken from spontaneous tumors can rapidly spread to the same areas affected by breast cancer in humans (11). The 4T1 murine breast carcinoma orthotropic model is an ideal system for the studying of the molecular, cellular, and pathological basis of breast cancer and metastatic disease, as well as the studying of therapeutic options.

In 2011, Kim et al. induced obesity in BALB/c female mice through a high-fat diet (HFD) and mammary carcinoma through the injection of $4 \mathrm{~T} 1$ cells in the mammary glands. It was observed that though there was not much impact on energy intake and body weight, HFD favored tumor growth, angiogenesis, metastases, as well as death among HFD, compared with mice fed with a standard diet (12). However, the systemic mechanisms underlining progression within this model still remain unclear. This work aimed to identify elements by which obesity affects breast cancer progression from primary tumors to sentinel lymph nodes and bone marrow, using an experimental $4 \mathrm{~T} 1$ murine breast carcinoma model in obese $\mathrm{BALB} / \mathrm{c}$ female mice.

\section{MATERIALS AND METHODS}

\section{Animals}

$\mathrm{BALB} / \mathrm{c}$ female mice aged 4 to 6 weeks were obtained from the colony of the Center for Reproductive Biology, Federal
University of Juiz de Fora. This study was performed following the principles of the Basel Declaration and recommendations of the Commission of Ethics in the Use of Animals of the Federal University of Juiz de Fora, approved protocol $\mathrm{N}^{\circ}$.038/2014-CEUA.

\section{Obesity Induction}

The animals were randomized before experimentation. Those designated as controls were fed standard commercial food (Nuvilab CR-1 ${ }^{\mathrm{TM}}$ ), having $10 \%$ of the kilocalories derived from lipids. The animals designated as obese received a high-fat diet, produced in our laboratory, where $57 \%$ of the kilocalories were derived from lipids, totalling $35.2 \%$ of lipids in the composition. Weight and food intake were monitored weekly for 16 weeks. Food consumption was measured twice a week; values were divided by seven days, and by the number of animals in each group. The Lee index and the weight of retroperitoneal and perigonadal fats were assessed after 16 weeks and 21 days on the high-fat or control diets.

\section{Biochemical Parameters}

A small blood sample from the tail vein of animals, previously fasted for $10 \mathrm{~h}$, was collected for the quantification of fasting glycaemia using a glucometer (ACCUCHECK Performa ${ }^{\mathrm{TM}}$ ). To perform the glucose tolerance test (GTT), $2 \mathrm{~g} / \mathrm{kg}$ body-weight of a $100 \mathrm{mg} / \mathrm{mL}$ glucose solution was administered intraperitoneally, and an additional glycaemia measurement was done after $60 \mathrm{~min}$.

Peripheral blood was collected by cardiac puncture following anesthesia of the animals. Total cholesterol and triglycerides were quantified using commercial kits (Labtest Diagnostica S/A) based on enzymatic colorimetric methods. Readings were performed using the Labmax Progress ${ }^{\circledR}$ (Labtest Diagnostica S/A). Serum leptin and fat leptin concentration were determined by ELISA (R\&D Systems ${ }^{\mathrm{TM}}$ ) following the manufacturer recommendations. Optical density reading was performed on a microplate reader (SPECTRAMAX 190, Molecular Devices) at $450 \mathrm{~nm}$. Biochemical parameters were determined on animals after 16 weeks on the high-fat or control diets.

\section{Cell Culture}

Cells of the murine 4T1 mammary carcinoma cell line were kindly given by Dr. Adriana Bonomo. Cells were grown in RPMI1640 culture medium $\left(\mathrm{GIBCO}^{\mathrm{TM}}\right)$ supplemented with $10 \%$ fetal bovine serum $\left(\mathrm{SFB}-\mathrm{GIBCO}^{\mathrm{TM}}\right)$ and $1 \%$ antibiotic/antimycotic solution $\left(100 \mathrm{IU} / \mathrm{mL}\right.$ penicillin and streptomycin-GIBCO $\left.{ }^{\mathrm{TM}}\right)$.

\section{Orthotopic Breast Cancer Model}

A model of transplantable tumors of syngeneic origin was used. After 16 weeks of diet initiation, $5 \times 10^{4} 4 \mathrm{~T} 1$ cells were injected subcutaneously (12), in a total volume of $100 \mu \mathrm{L}$, into the region of the first right inguinal mammary gland. All animals continued to be fed their respective diets until euthanasia. Tumor volume was measured using a caliper after 14, 17, 24, and 30 days of induction and calculated according to the formula: largest diameter $\times(\text { smallest diameter })^{2} \times 0.52(12)$. After euthanasia, tumors were collected and weighed. 


\section{Metastatic Clonogenic Assay}

Tumor-derived peripheral draining inguinal lymph node cells were removed, macerated, and suspended in DMEM medium $\left(\mathrm{GIBCO}^{\mathrm{TM}}\right)$ supplemented with 10\% FBS. Iliac bones were collected and incubated for $1 \mathrm{~h}$ in DMEM medium supplemented with $10 \%$ FBS, $0.5 \mathrm{mg} / \mathrm{mL}$ collagenase type I (SIGMA $\mathrm{ALDRICH}^{\mathrm{TM}}$ ) and $100 \mu \mathrm{g} / \mathrm{mL}$ DNAse (SIGMA-ALDRICH ${ }^{\mathrm{TM}}$ ). Tumor-derived cells and bone marrow cells were harvested and plated at $10^{6}$ cells $/ \mathrm{mL}$ per well in 6-well plates, and serial dilutions were performed until the minimum concentration of 10 cells $/ \mathrm{mL}$ was reached. The culture was maintained at $37^{\circ} \mathrm{C}$ and $5 \% \mathrm{CO}_{2}$ for 14 days. Cells were harvested, fixed with methanol (Synth ${ }^{\mathrm{TM}}$ ) and stained with $1 \%$ methylene blue (Merck Millipore ${ }^{\mathrm{TM}}$ ) for tumor cells' clusters quantification. The time-points assessed in this assay were selected based on previous work published by Monteiro et al. (13).

\section{Fat-Conditioned Medium}

Perigonadal fats derived from obese and control mice were extracted, weighed, and sterilely washed. Hundred micro gram of fats were manually chopped and cultured with $1 \mathrm{~mL}$ of M199 medium $\left(\mathrm{GIBCO}^{\mathrm{TM}}\right)$ for $24 \mathrm{~h}$. Culture supernatant was collected, centrifuged to remove cell debris, filtered using a $0.22 \mu \mathrm{m}$ Millex ${ }^{\circledR} \mathrm{GP}$ (Merck Millipore) and stored at $-80^{\circ} \mathrm{C}$ until use.

\section{T1 Cells Migration Assay}

Fresh $4 \mathrm{~T} 1$ cells were pre-cultured for $72 \mathrm{~h}$ with $50 \%$ fatconditioned medium (derived from obese or control mice) in RPMI-1640 culture medium (GIBCO ${ }^{\mathrm{TM}}$ ), supplemented with $10 \%$ fetal bovine serum and $1 \%$ antibiotic and antimycotic (100 $\mathrm{IU} / \mathrm{mL}$ penicillin and streptomycin-GIBCO $\left.{ }^{\mathrm{TM}}\right) .10^{5}$ cells were plated in RPMI-1640 without FBS in the upper chamber of a Transwell ${ }^{\circledR}$ plate $(6.5 \mathrm{~mm}$ diameter and $8 \mu \mathrm{m}$ pore sizeCorning Incorporated $\left.\operatorname{Costar}^{\circledR}\right)$. As a migratory stimulus, $400 \mathrm{ng} / \mathrm{mL}$ of each CXCL12 and CCL25 in RPMI-1640 without FBS was placed in the lower chamber. After $6 \mathrm{~h}$, the membrane of the upper well was fixed and stained with Panotico kit (Laborclin). Cells were counted in a microscope using the NISElement BR 3.2 software (Nikon).

\section{Characterization of Immune Cells by Flow Cytometry}

The pools of draining inguinal lymph nodes were harvested and $10^{6}$ cells per well plated to perform cell labeling with the following antibodies: anti-CD11b (Alexa 488), anti-CD11c (APCCy7), antiCD80 (APC), and anti-CD86 (PE) for myeloid cells; anti-CD3 (APCCy7), anti-CD8 (Alexa 647), anti-CD4 (FITC), and anti$\mathrm{CD} 25$ (PECy7) for $\mathrm{T}$ cells; anti-Foxp3 (PE) for regulatory $\mathrm{T}$ cells (all antibodies purchased from BD Biosciences ${ }^{\mathrm{TM}}$ ). The samples were acquired on the BD FACSCanto $\mathrm{II}^{\mathrm{TM}}$ cytometer and data analyzed using FlowJo v10 (LLC). Gating strategy: Lymphocytes and myeloid cells were initially gated based on size and granularity (FSC X SSC). On the lymphocytes, a gate for $\mathrm{CD}^{+}$was drawn to label T cells. From this gate, a CD4 vs. CD8 plot was drawn to separate $\mathrm{CD}^{+}$and $\mathrm{CD}^{+} \mathrm{T}$ cells. Within each of these populations, a graph plotting CD25 and FoxP3 was used to delineate regulatory $\mathrm{T}$ cells. Cells with larger size and granularity were then selected and gated for $\mathrm{CD}_{11 \mathrm{~b}}{ }^{+}$and $\mathrm{CD}_{11 \mathrm{c}^{+}}$to select macrophages and DCs, respectively. Within each of these populations, a CD80 vs. CD86 plot was drawn to determine the double positive cells.

\section{ELISA}

The concentration of TNF- $\alpha$ and IL- 6 was measured in the culture supernatants of bone marrow cells, previously harvested and plated at $10^{7}$ cells $/ \mathrm{mL}$ per well in 96-well culture plate and incubated with $1 \mathrm{ug} / \mathrm{mL}$ anti-CD3 (BD Biosciences ${ }^{\mathrm{TM}}$ ) for $72 \mathrm{~h}$. For measurements, commercial kits (R \& D Systems) were used following the manufacturer recommendations. Analyses were performed on a microplate reader (SPECTRAMAX 190, Molecular Devices) at $450 \mathrm{~nm}$. Quantification of the cytokines was calculated from the standard curves obtained from the different concentrations of each recombinant protein.

\section{Bioinformatic Analysis}

Microarray data of human triple-negative breast cancer (TNBC) tumors were obtained from GEO, access number GSE76124 (14) and analyzed with limma and Biobase $\mathrm{R}$ packages ( $\mathrm{R}$ version 3.6.0, Bioconductor version 3.9). Women were considered "healthy" or non-obese if BMI ranged from 16 to $24(n=49)$, with overweight if BMI ranged from 25 to $29(n=93)$, and obese when BMI was $>30$ (ranged from 30 to 46$)(n=56)$. Heatmap was constructed with pheatmap R package. Spearman correlation tests and plots were made by corrplot $\mathrm{R}$ package (15) using immune cells percentage obtained from CIBERSORT (16) output and normalized gene values. The correlation was considered significant if $p$-value $<0.05$.

\section{Statistical Analysis}

Graphs and statistical analyses were performed using GraphPad Prism 5.0 (GraphPad Software). After KolmogorovSmirnov normality tests, the data were submitted to the unpaired $t$-test or Mann-Whitney test. Data on body weight, food intake, and clonogenic assays were analyzed by two-way ANOVA followed by Sidak's multiple comparisons post-test. Data in graphs are presented as mean values and their corresponding standard deviation. The difference between groups was considered significant when $p \leq 0.05$.

\section{RESULTS}

\section{HFD Induces Obesity and Metabolic Impairment}

To evaluate the induction of obesity, corporal, and biochemical changes in control and HFD-fed mice were analyzed. After 2 weeks and through the following 14 weeks, the weight of HFD-fed mice was significantly higher than the weight of control mice; HFD-fed mice were, on average, 4.77 grams heavier than control mice (Figure 1A). During all 16 weeks, HFD-fed mice presented lower mean food intake than control mice, whereas the mean food intake of HFD in kilocalories (Kcal) was 

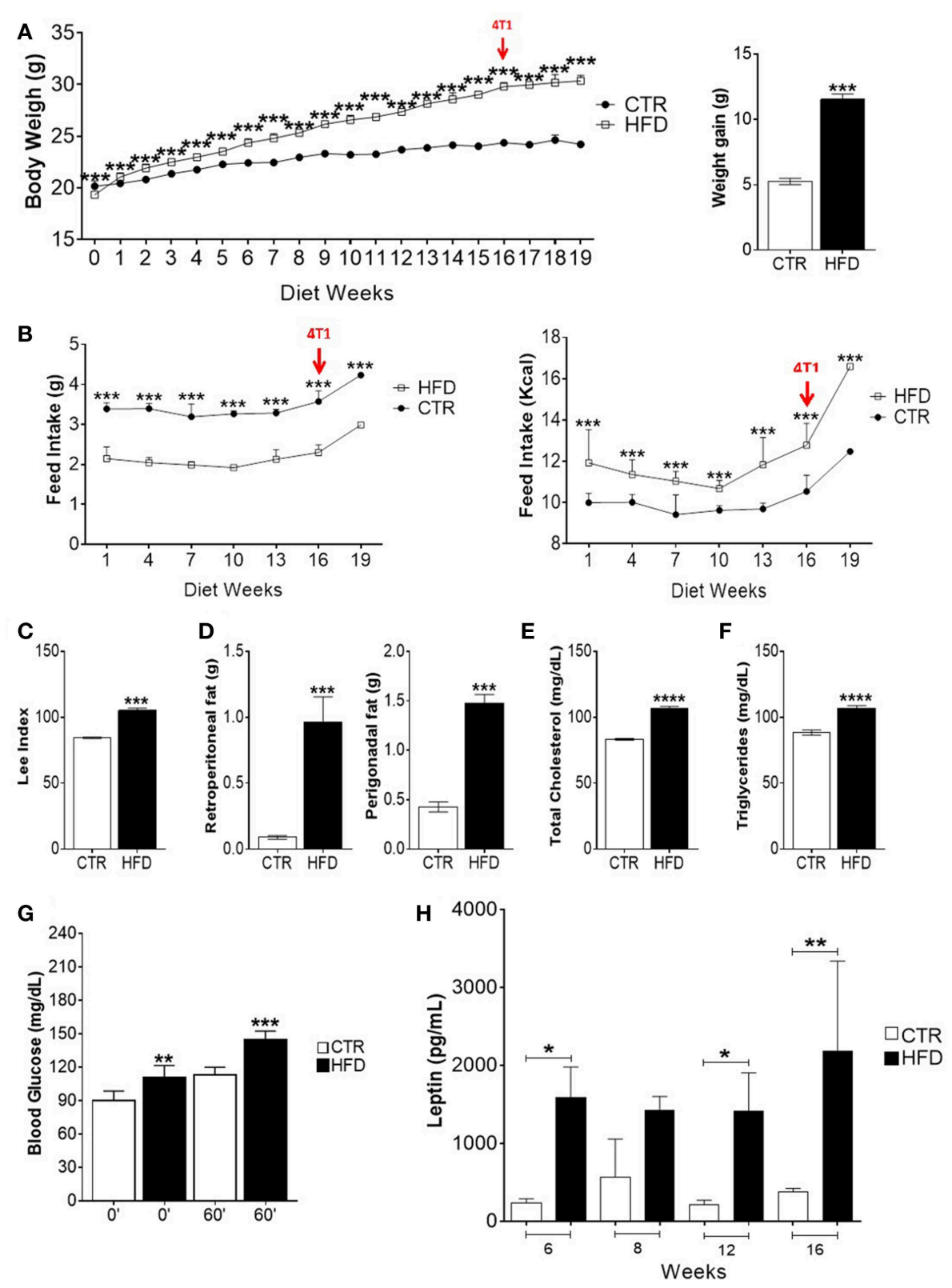

FIGURE 1 | High-fat diet induces obesity, metabolic impairment and high leptin levels in BALB/c mice. (A) Body weight gain per week (left) and overall body weight gain (right); (B) food intake (left) and caloric intake (right) per week; (C) Lee index; (D) weight of retroperitoneal and perigonadal fats; (E) total serum cholesterol; (F) serum triglycerides; (G) blood glucose; (H) serum leptin. CTR, control animals; HFD, obese animals. Each bar represents the mean \pm SD. ${ }^{*}$ Denotes significant differences between obese vs. control group, being ${ }^{*} p \leq 0.05 ;{ }^{* *} p \leq 0.01 ;{ }^{* \star *} p \leq 0.001 ;{ }^{* \star \star *} p \leq 0.0001(n=116$ controls and $n=116$ obese-A,B) $(n=90$ controls and $n=75$ obese-C) $(n=112$ controls and $n=118$ obese--D) $(n=5$ controls and $n=5$ obese-E-G).

higher than mice fed standard diet (Figure 1B). HFDfed mice presented an increased Lee index (Figure 1C) as well as weightier retroperitoneal and perigonadal fats (Figure 1D). Regarding their metabolic profile, HFD-fed mice presented higher serum levels of total cholesterol (Figure 1E) triglycerides (Figure 1F), glycaemia after receiving glucose (Figure 1G) and leptin (Figure 1H), compared with control mice.

\section{Tumor Progression Is Accelerated in Obese Mice}

To evaluate the effect of obesity in tumor progression, HFDfed, and control mice were injected with $4 \mathrm{~T} 1$ tumor cells after 16 weeks of diet and monitored for several days, during which different experiments were performed (Figure 2A). The survival of obese mice was lower than the survival of control mice, although no statistically significant differences were 


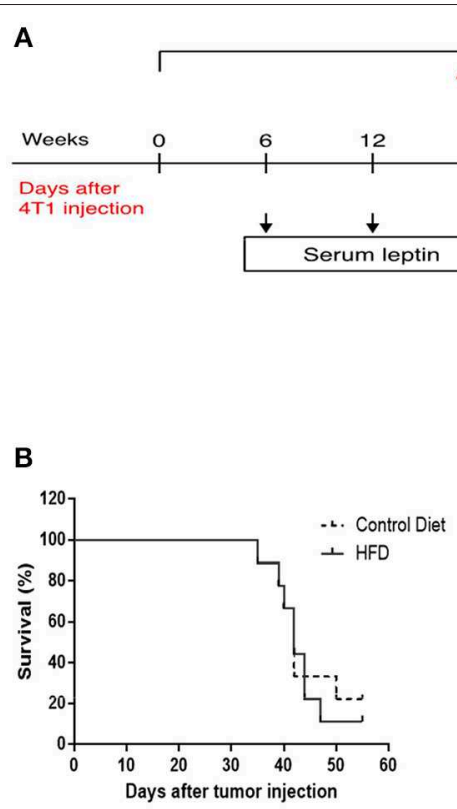

C HFD or CTR

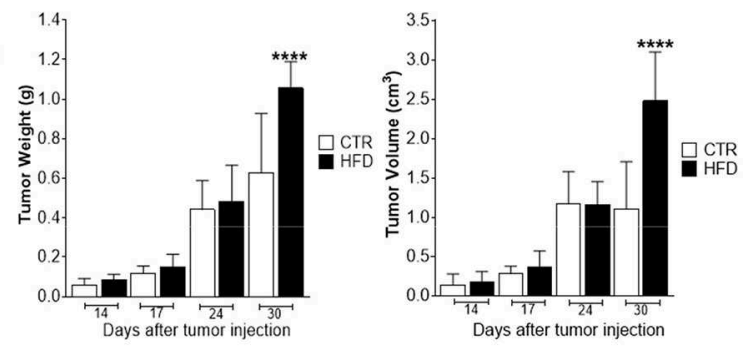

D
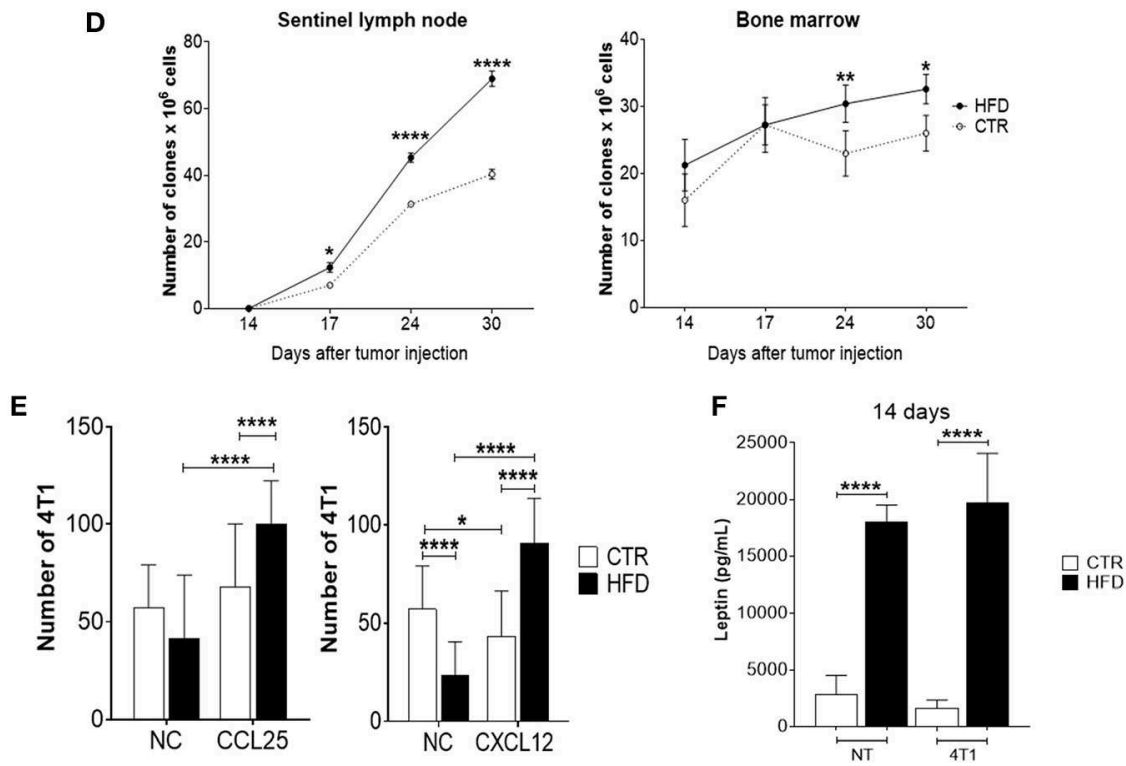

FIGURE 2 | Obese mice exhibit accelerated 4T1 tumor progression and metastasis. (A) Experimental timeline; (B) survival; (C) tumor weight (left) and volume (right); (D) number of 4T1 cell clones found in sentinel lymph nodes (left) and bone marrow (right); (E) number of fresh 4T1 cells (previously treated with fat-conditioned medium from obese and control animals) found in transwell membranes after migration through CCL25 (left) and CXCL12 (right) gradients; (F) leptin levels in fat from obese and control animals with and without 4T1 tumors. CTR, control animals; HFD, obese animals; NC, no chemokines; NT, no tumor. Each bar represents the mean \pm SD. ${ }^{\star}$ Denotes significant differences between obese vs. control group, being ${ }^{\star} p \leq 0.05 ;{ }^{* \star} p \leq 0.01 ;{ }^{* \star *} p \leq 0.001 ;{ }^{* \star \star \star} p \leq 0.0001$ ( $n=5$ controls and $n=5$ obese).

observed (Figure 2B). As the disease progressed, there was a significant increment in tumor weight and volume of obese mice (Figure 2C). After 55 days of 4T1 cells' injection, 22\% of control mice survived compared with $11 \%$ within the obese group.

To investigate metastases, a clonogenic assay with 4T1 cells derived from metastatic niches was performed based on previous work done by Monteiro et al. (13). Interestingly, a progressive increase of $4 \mathrm{~T} 1$ clones was observed in tumor sentinel lymph nodes of obese mice with a significant difference after 17 days of tumor cells injection, compared to controls; similar results were found in the bone marrow which presented an increase of 4T1 cell clones after 24 days of tumor cells injection (Figure 2D).

To explore the mechanism by which $4 \mathrm{~T} 1$ cells infiltrating the metastatic niches have higher metastatic potential in the obese mice, a transwell migration assay was performed. Fresh 4T1 cells cultured in the presence of conditioned medium containing fat from obese mice exhibited increased migration after CXCL12 and CCL25 stimulus, compared with 
4T1 cells cultured with conditioned medium containing fat from control mice (Figure 2E). Notably, increased levels of leptin were found in the conditioned medium containing fat removed from obese mice compared with the conditioned medium containing fat removed from controls (Figure 2F).

\section{Cancer Sentinel Lymph Nodes of Obese Mice Have Reduced Infiltration and Activation of Immune Cells}

To characterize the immune response triggered by the tumor in obese and control mice, the populations of immune cells present in tumor-draining lymph nodes were analyzed. The characterization of immune cells was done on day 21 st based on the results obtained from the clonogenic assay: the increment of the clonogenic potential of $4 \mathrm{~T} 1$ cells was first observed after 17 days of 4T1 injection, reaching higher statistical significance at day 24th. Thus, day 21st was chosen as an average day for the evaluation of immune populations within tumor-draining lymph nodes (Figure 2A). A significant drop in the mean number of total $\mathrm{CD}^{+} \mathrm{T}$ cells was observed in obese mice compared with controls (Figure $3 \mathrm{~A}$ ); both, $\mathrm{CD} 4^{+}$and $\mathrm{CD}^{+}$populations were affected (Figures 3B,C). An increased number of activated $\mathrm{CD} 4^{+} \mathrm{CD} 25^{+} \mathrm{T}$ cells were found in obese mice; however, within this population, CD25 was expressed in lower levels (MFI) than in controls (Figure 3D). The same phenomenon was observed within activated $\mathrm{CD} 8^{+} \mathrm{CD} 25^{+} \mathrm{T}$ cells (Figure 3F). On the other hand, the number of regulatory $\mathrm{CD} 4^{+} \mathrm{CD} 25^{+} \mathrm{Foxp}^{+}$ and $\mathrm{CD} 8^{+} \mathrm{CD} 25^{+}$Foxp $^{+} \mathrm{T}$ cells were significantly decreased in obese mice (Figures 3E,G); however, higher levels (MFI) of the Foxp 3 transcription factor was observed within the $\mathrm{CD} 8^{+}$ regulatory population (Figure 3G). No difference was found on CD25 levels (MFI) within regulatory populations between obese and control mice (data not shown). CD25 levels were higher in regulatory compared to non-regulatory $\mathrm{T}$ cells, regardless if they were found in the lymph nodes of obese or control mice (data not shown).

Regarding myeloid populations, numbers of $\mathrm{CD}_{11 \mathrm{~b}^{+}}$ macrophages, and $\mathrm{CD}_{11 \mathrm{c}^{+}}$dendritic cells (DCs) were also decreased in draining lymph nodes of obese mice compared with controls (Figures 4A,B); both cells also presented low expression (MFI) of co-stimulatory molecules CD80 and CD86.

\section{Obesity Impairs Levels of Bone Marrow-Derived Cytokines in Mice Bearing 4T1 Tumors}

To further investigate the role of obesity in favoring the disruption of haematopoiesis promoted by the increased metastatic potential of $4 \mathrm{~T} 1$ cells, the level of two cytokines necessary for the development of lymphocyte and myeloid precursors in the bone marrow were analyzed. Notably, only obese mice that received $4 \mathrm{~T} 1$ cells have both levels of IL6 (Figure 4C) and TNF- $\alpha$ (Figure 4D) significantly reduced in the bone marrow, compared to controls and obese mice without tumors.

\section{Reduced Infiltration of CD8 T Cells in Human Triple-Negative BC Tumors From Obese Patients Is Correlated With Leptin, CXCR4, and CCR9}

Based on our murine model, we hypothesized that CXCR4 and CCR9 receptors might be upregulated in breast cancer cells derived from primary tumors of obese individuals. To investigate this, we performed a bioinformatic analysis using microarray data from the GEO GSE76124 dataset. No differences were found in the expression of CXCL12, LEP, CXCR4, CCL25, CCR9, or $L E P R$ genes in primary triple-negative $\mathrm{BC}$ tumors from nonobese ("healthy"), obese or overweighted patients (Figure 5A). Using the CIBERSORT tool, we found that CD8 T cells were significantly decreased in obese patients compared to non-obese (Figures 5B,C). Our correlation analysis (Figure 5D) showed that CXCL12 and CXCR4 had a negative correlation with CD8 T cells on both groups. In obese patients (BMI >30), CCR9 was negatively correlated with CD8 $\mathrm{T}$ cell infiltration, whereas was positively correlated, together with CCL25 in the non-obese (BMI $<25)$. On the other hand, $L E P$ was positively correlated with its receptor, $L E P R$ only in obese patients. $L E P$ and $L E P R$ were negatively correlated with CD8 T cell infiltration in the obese, whereas no correlation was found in the non-obese. The positive correlation between LEP and CXCL12 was higher in the obese, whereas the positive correlation between LEPR and CCL25 was higher in the non-obese. Despite being increased in the obese, the LEP-CXCL12-CCR4 network could play a negative role in breast cancer per se, whereas obesity might play a role in the functional switch of the LEPR-CCR9-CCL25 network, from promoting tumor immune infiltration in the non-obese, to ultimately favor tumor metastasis in the obese.

\section{DISCUSSION}

Obesity is a significant risk factor for the development of breast malignancies. Still, the mechanisms underlining breast cancer progression among obese women remain unclear. Using a diet-induced obesity murine model of $4 \mathrm{~T} 1 \mathrm{mammary}$ carcinoma in $\mathrm{BALB} / \mathrm{c}$ female mice previously fed with a HFD, we showed that fat derived from obese mice favored tumor progression by accelerating the metastatic potential of 4T1 cells within the metastatic niches, thus, disrupting antitumoral cell-mediated immunity in tumor-draining lymph nodes and deregulating haematopoiesis-related cytokines in the bone marrow (Figure 6).

Leptin has been acknowledged to be a critical element of the obesity-related progression and malignancy of breast cancer (17). Leptin can directly remodel the tumor microenvironment by inducing metabolic changes in tumor cells and recruiting immune cells such as monocytes, macrophages and myeloid-derived suppressor cells (MDSCs) able to produce proinflammatory cytokines that sustain angiogenesis and tumor growth (18). It was previously shown that the proliferation of $4 \mathrm{~T} 1$ cells in vitro increased by the addition of leptin; also, that the inhibition of leptin-mediated signaling on these cells reduces its proliferation and the growth of $4 \mathrm{~T} 1$ tumors in vivo (19). 


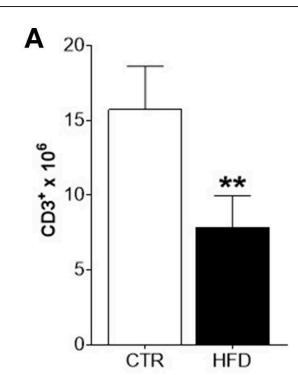

B
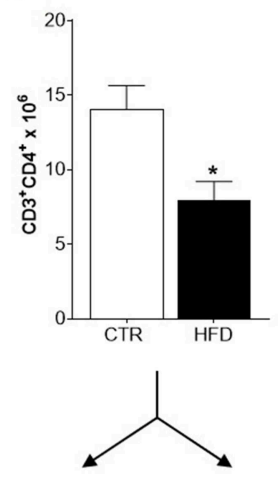

D

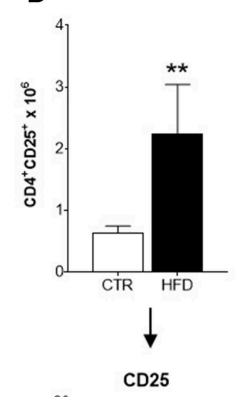

E
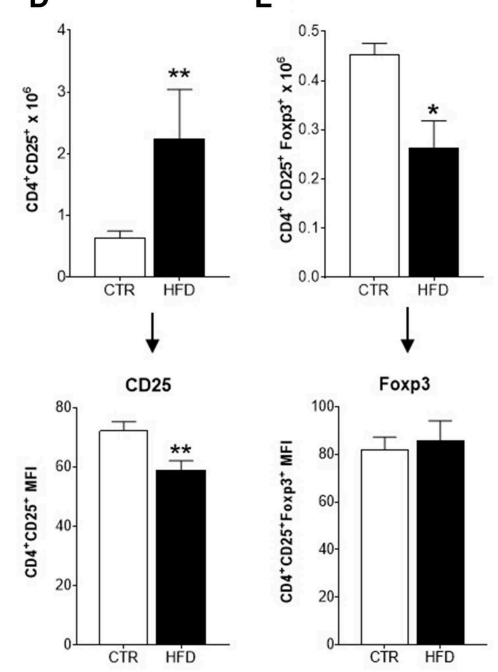

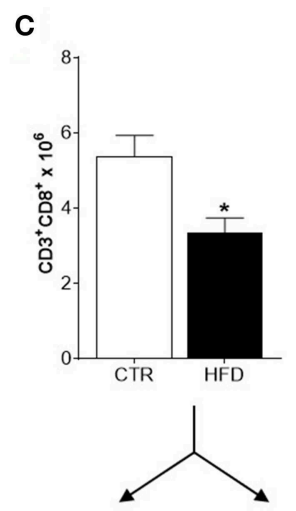

$\mathbf{F}$
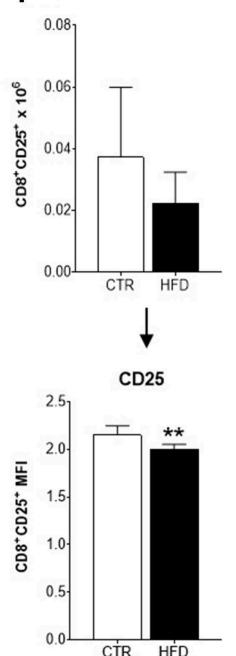

G

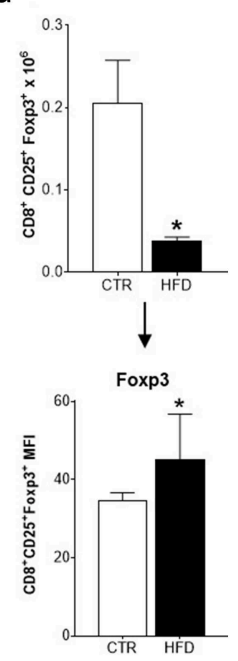

FIGURE 3 | Infiltration and activation of T cells is disrupted in cancer-sentinel lymph nodes of obese mice. (A) Number of total CD3 ${ }^{+} \mathrm{T}$ cells; (B) number of total $\mathrm{CD}^{+} \mathrm{CD}^{+} \mathrm{T}$ cells; (C) number of total CD3 ${ }^{+} \mathrm{CD} 8^{+} \mathrm{T}$ cells; (D) number of $\mathrm{CD} 4^{+} \mathrm{CD} 25^{+} \mathrm{T}$ cells (top) and CD25 expression (MFI) within them (bottom); (E) number of $\mathrm{CD}^{+}{ }^{+} \mathrm{CD} 25^{+}$Foxp3 $^{+} \mathrm{T}$ cells (top) and Foxp3 expression (MFI) within them (bottom); (F) number of $\mathrm{CD}^{+}{ }^{+} \mathrm{CD} 25^{+} \mathrm{T}$ cells (top) and CD25 expression (MFI) within them (bottom); (G) number of CD8 ${ }^{+}$CD25 ${ }^{+}$Foxp3 ${ }^{+}$T cells (top) and Foxp3 expression (MFI) within them (bottom). CTR, control animals; HFD, obese animals. Each bar represents the mean \pm SD. ${ }^{*}$ Denotes significant differences between obese vs. control group, being ${ }^{*} p \leq 0.05 ;{ }^{* *} p \leq 0.01$ ( $n=5$ controls and $n=5$ obese).

We showed that fat derived from obese mice, which contain high levels of leptin, induces the migration of $4 \mathrm{~T} 1$ cells through a transwell membrane, following the gradient of CCL25 and CXCL12; although both chemokines recruit immune cells to inflammatory tissues, they have also been linked to invasion and metastasis of cancer cells $(20,21)$. These findings are in agreement with the increased clonogenic potential of $4 \mathrm{~T} 1$ cells found in tumor-draining lymph nodes and bone marrow. Leptin has been found to increase the levels of CXCR4 (the CXCL12 receptor) in bone marrow-derived mesenchymal stem cells (22) and to increased CCR9 expression (the CCL25 receptor) on hepatic stellate cells (23). The CXCL12/CXCR4 axis is strongly correlated with breast cancer aggressiveness and metastasis (20), whereas the CCL25/CCR9 axis provides chemotherapy resistance to breast cancer cells (21). Interestingly, from the analysis of the microarray data of the GEO GSE76124 dataset, we observed that the genes for leptin, CXCR4, and CCR9 are correlated with reduced infiltration of CD8 T cells in human triple-negative $\mathrm{BC}$ tumors from obese patients. CD8 T cells are considered a favorable prognosis marker for several cancer types, including breast cancer $(24,25)$; worse outcomes are expected in patients with tumors poorly infiltrated by them, suggesting that obese patients might have disease progression sooner than non-obese, as we observed in our 4T1 mice model. 


\section{A}
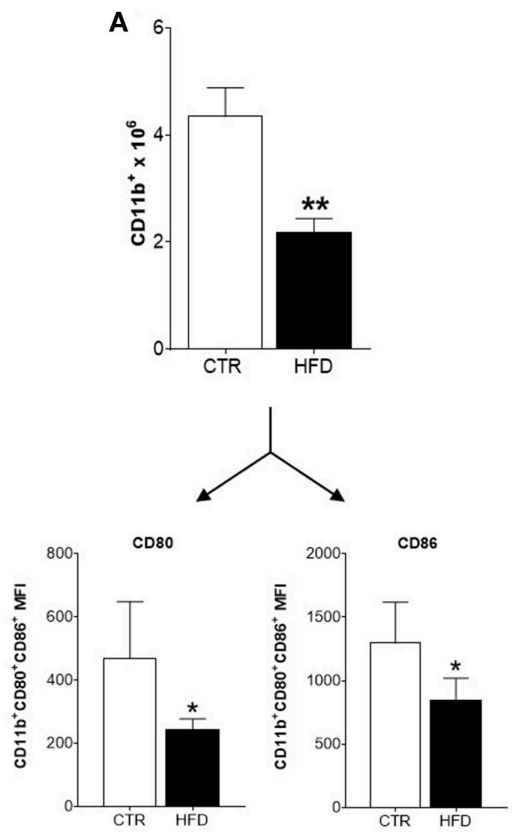

C

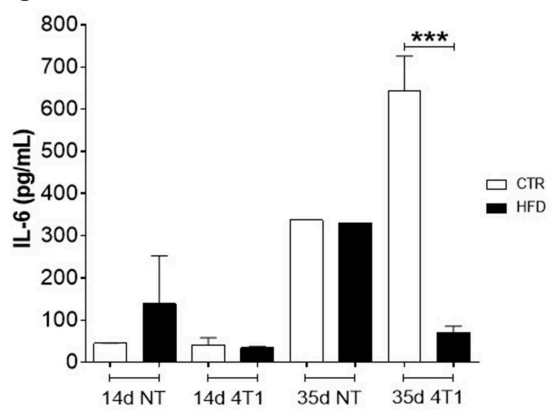

B
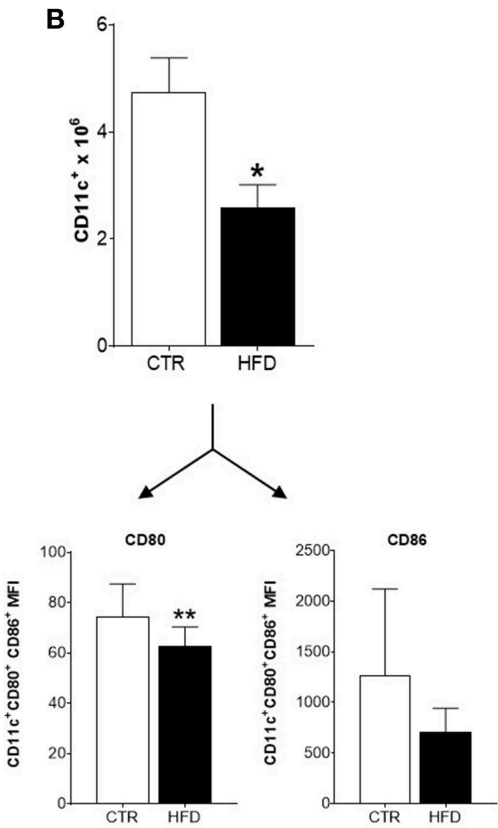

D

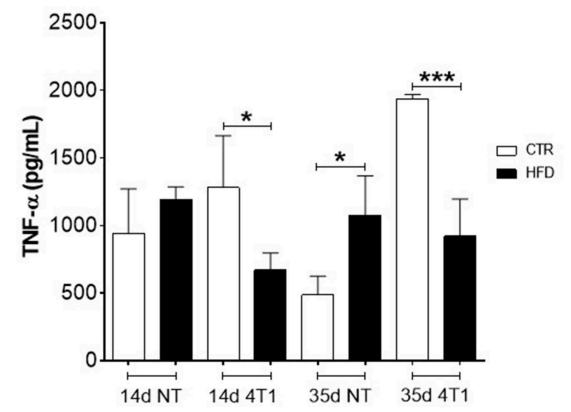

FIGURE 4 | Obese mice exhibit reduced infiltration of myeloid cells within cancer-sentinel lymph nodes and deregulation of haematopoiesis-related cytokines in the bone marrow. (A) Number of total CD11 b ${ }^{+}$macrophages (top) and expression (MFI) of CD80 and CD86 within the CD11b+ $\mathrm{CD}^{+} 0^{+} \mathrm{CD}^{+} 6^{+}$population (bottom); (B) Number of total CD11 ${ }^{+}$dendritic cells (top) and expression (MFI) of CD80 and CD86 within the CD11 ${ }^{+} \mathrm{CD}^{+} 0^{+} \mathrm{CD}^{+} 6^{+}$population (bottom); (C) Levels of IL-6 and (D) TNF- $\alpha$ in the bone marrow of obese and control animals with and without 4T1 tumors. CTR, control animals; HFD, obese animals; NT, no tumor. Each bar represents the mean $\pm \mathrm{SD}$. ${ }^{\star}$ Denotes significant differences between obese vs. control group, being ${ }^{*} p \leq 0.05$; ${ }^{\star \star} p \leq 0.01 ;{ }^{* \star *} p \leq 0.001$ ( $n=5$ controls and $n=5$ obese).

Our data provide a plausible explanation by which obesity worsen breast cancer progression through expose breast cancer cells to high leptin levels, that ultimately favor the chemokine networks that, not only hamper CD8 T cell infiltration to the tumor but instead, are used by cancer cells to spread and metastasize.

The immune profiling of tumor-sentinel lymph nodes is a clinically valuable tool to predict breast cancer prognosis (26). We found that immune cells poorly infiltrate tumordraining lymph nodes of obese mice; all populations were decreased, including subsets related to tumor progression, such as regulatory $\mathrm{T}$ cells and macrophages. Interestingly, an increased number of $\mathrm{CD} 4^{+} \mathrm{CD} 25^{+} \mathrm{T}$ cells were found in obese mice, expressing lower levels of CD25 (the IL-2R alpha chain) than $\mathrm{CD}^{+} \mathrm{CD}^{+} 5^{+} \mathrm{T}$ cells found in nonobese mice. Downregulation of CD25 within activated T cells is linked to defective signaling that leads to unresponsive or anergic $\mathrm{T}$ cell clones $(27,28)$. This phenomenon might be supported by the reduced expression of co-stimulatory molecules found in DCs and macrophages within tumordraining lymph nodes. Also, CD25 lost within activated T cells might be induced by competition for IL-2 between activated and regulatory $\mathrm{T}$ cells expressing higher levels of Foxp3, which has been directly associated with their potential to suppress the activation of effector $\mathrm{T}$ cells and correlated with cancer progression $(29,30)$.

Typically, myeloid cells are increased within the tumor microenvironment and pre-metastatic niches to promote tumor 
A

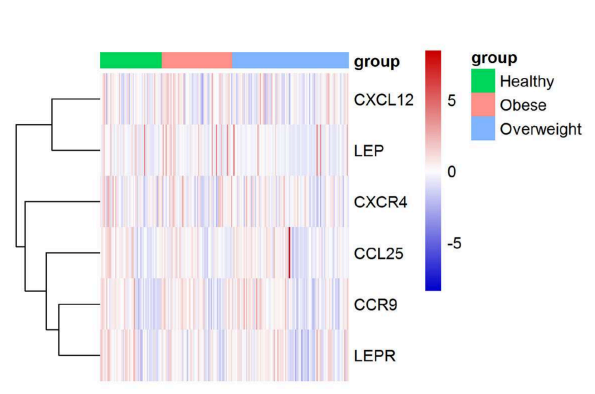

C

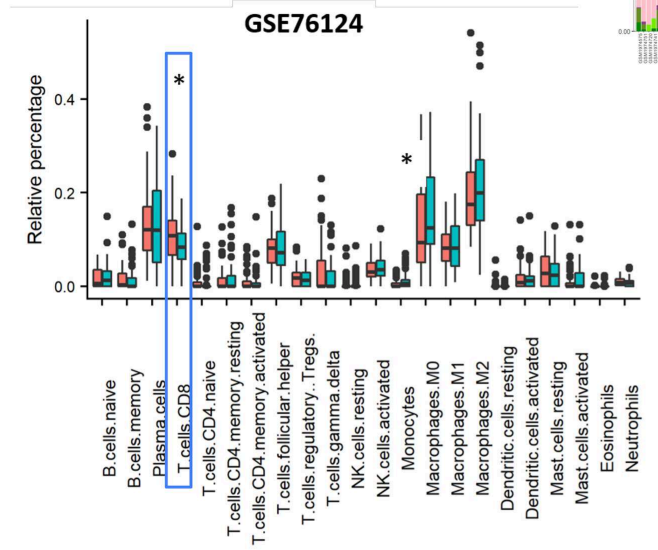

D

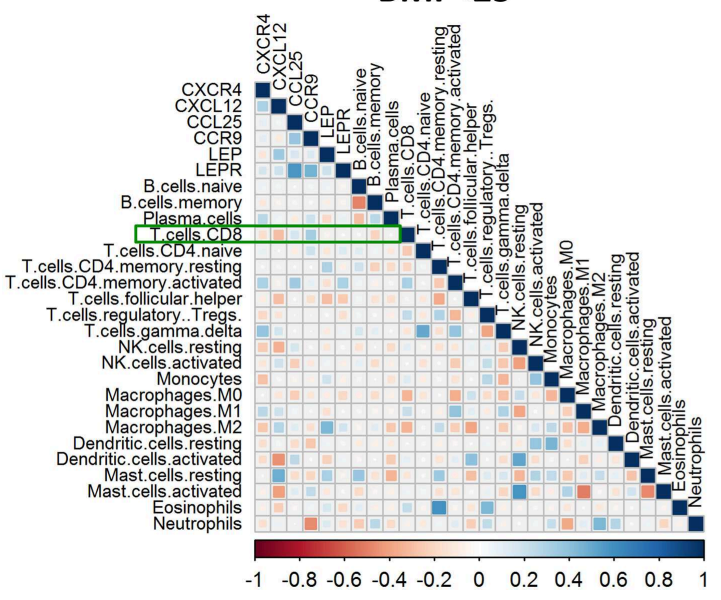

B

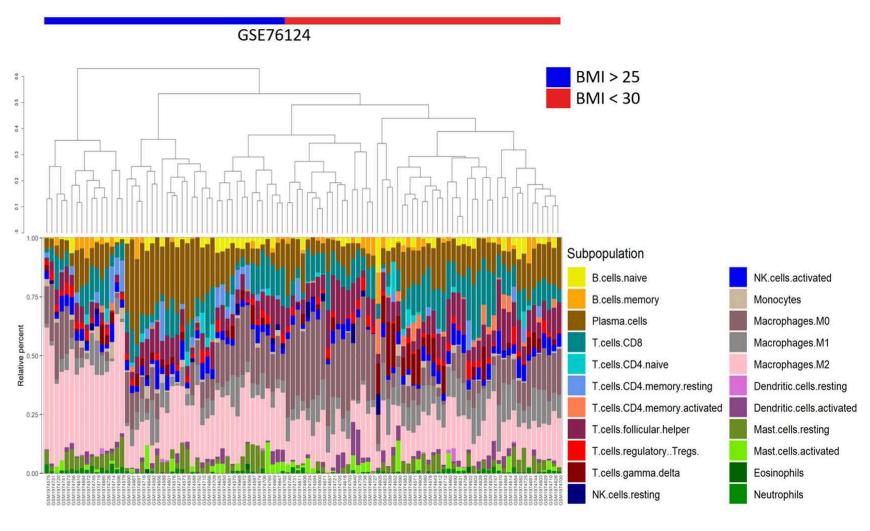

帛 $\mathrm{BMI}<25$

帛 $\mathrm{BMI}>30$

FIGURE 5 | Poor infiltration of CD8 T cells in human triple-negative BC tumors from obese patients is correlated with leptin, CXCR4, and CCR9. (A) Gene expression heatmap of genes of interest on primary triple-negative BC tumors from obese and non-obese "healthy" patients. (B) Abundance and (C) relative percentage of CIBERSORT populations of immune cells infiltrating primary triple-negative BC tumors from obese and non-obese "healthy" patients. (D) Correlation between immune cell populations and CXCR4/CXCL12, CCR9/CCL25, and Leptin/Leptin receptor (LEP/LEPR) in primary triple-negative BC tumors from obese and non-obese "healthy" patients. Blue squares represent positive correlations and red squares represent negative correlations where statistically significant differences were found; White dots represent correlations where no statistically significant differences were found. * $p \leq 0.05$ ( $n=49$ "healthy" or non-obese patients, $n=93$ overweighted patients and $n=56$ obese patients from the GSE76124 dataset).

survival and metastases $(31,32)$. Obesity seems to disturb this scenario; after 6 weeks of HFD, bone marrow malfunction is induced by a mechanism depending on LPS originated from bacteria (translocated from the gut to the bloodstream) that stimulate, via TLR4, myelopoiesis instead of lymphopoiesis (33).
However, as obesity accelerates tumor progression, the increment of DCs or macrophages is not reflected within tumor-draining lymph nodes, and both populations within them were also compromised. A possible boost of MDSCs cannot be ruled out; although it was not directly measured in our model, MDSCs are 


\section{The role of obesity in the progression of murine 4T1 mammary carcinoma}

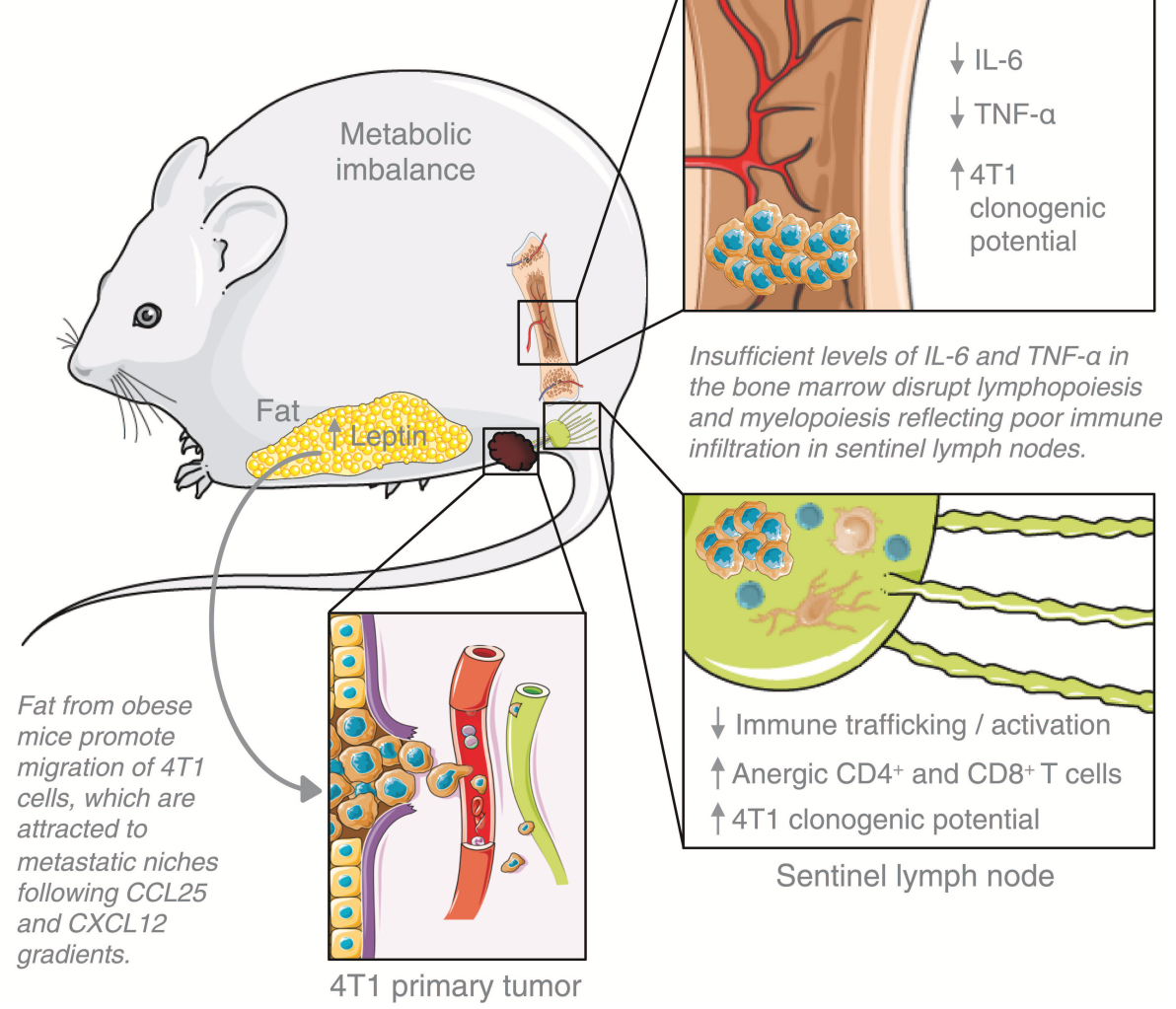

FIGURE 6 | Elements of breast cancer progression triggered by obesity. This figure is a derivative created by the author MC-S using images from Servier Medical Art by Les Laboratoires Servier (https://smart.servier.com/). Original images are licensed under a Creative Commons Attribution 3.0 Unported License (https:// creativecommons.org/licenses/by/3.0/).

induced after prolonged chronic inflammation, such as obesity, once their development can be triggered by fatty acids $(34,35)$. Within the metastatic niches, these cells have been shown to interfere and suppress tumor-specific $\mathrm{T}$ cell responses as well as myeloid cells (36) whereas their blockage can restore DCs and macrophages activation (37). Instead of a consequence of the high-fat diet per se (38), immunosuppression could result as a consequence of the accelerated progression promoted by the HFD, which could also cause trafficking disruption of immune cells to the lymph nodes. Indeed, cancer-induced remodeling of high endothelial venules (HEVs) is a distinctive feature of premetastatic sentinel lymph nodes, which results in a functional shifting of HEVs that facilitates the blood flow into the tumors (39). Also, immunosuppression in obese animals may be linked to a possible hematopoietic dysfunction caused by bone marrow metastases. A reduction in blood T cell populations of mice HFDfed has been attributed to the loss of balance between skeletal and immune systems, resulting in the dysfunction of haematopoiesis (40). Within the cytokines involved in the process, IL-6 and TNF$\alpha$ decreased in the bone marrow of obese animals, whereas levels of both cytokines increased in the non-obese, after 4T1 cells injection. Increased pro-inflammatory cytokines such as TNF- $\alpha$,
IL-1, IL-6, and $\mathrm{PGE}_{2}$ are hallmarks of obesity and obesityinduced breast cancer development $(8,41)$. However, in a state of accelerated progression induced by obesity, a detriment of pro-inflammatory IL- 6 and TNF- $\alpha$ production within the bone marrow may support the disruption of both myelopoiesis and lymphopoiesis $(31,42,43)$. Low levels of both cytokines could also be caused by its consumption by $4 \mathrm{~T} 1$ cells infiltrating the bone marrow, which are known to express IL- 6 and TNF- $\alpha$ receptors and to trigger their signaling pathways after in vitro treatment with the cytokines (44).

In conclusion, our work present early evidence by which obesity promotes breast cancer progression from a systemic point of view, beyond the tumor microenvironment. Moreover, we show that the changes observed within the tumor (12) do not reflect on the systemic response here assessed. Still, more studies are needed to connect the leptin-CXCL12-CCL25 axis and to define the possible role of MDSCs in the breast cancer accelerated immunosuppression and progression promoted by high-fat-dietinduced obesity. Targeting these pathways, probably involved in the paving of pre-metastatic niches, might be useful to prevent the rapid breast cancer progression observed among obese patients. 


\section{DATA AVAILABILITY}

All datasets generated for this study are included in the manuscript/supplementary files.

\section{ETHICS STATEMENT}

This study was carried out in accordance with the principles of the Basel Declaration and recommendations of Commission of Ethics in the Use of Animals of the Federal University of Juiz de Fora, that approval the protocol $\mathrm{N}^{\circ}$. 038/2014-CEUA.

\section{AUTHOR CONTRIBUTIONS}

GE, PS, and JG conceived the experiments. GE, PS, SS, FX, LA, AG, and GM conducted the experiments. GE and PS analyzed the results. MC-S and LB performed the bioinformatic analysis. MC-S interpreted the data and wrote the manuscript along with GE and PS. All authors reviewed the final version of the manuscript.

\section{REFERENCES}

1. WHO. Obesity and Overweight: Fact Sheet. 311. (2016) Available online at: https://www.who.int/news-room/fact-sheets/detail/obesity-and-overweight (accessed February 25, 2018).

2. World Health Organization. Key Facts: What Causes Cancer? (2018) Available online at: https://www.who.int/news-room/fact-sheets/detail/ cancer (accessed February 25, 2018).

3. Stewart BW, Wild CP. World Cancer Report 2014. Lyon: International Agency for Research on Cancer. (2014).

4. Secretan BL, Scoccianti C, Loomis D, Grosse Y, Bianchini F, Straif K. Body fatness and cancer - viewpoint of the IARC working group. $N$ Engl J Med. (2016) 375:794-8. doi: 10.1056/NEJMsr1606602

5. Kroenke $\mathrm{CH}$, Chen WY, Rosner B, Holmes MD. Weight, weight gain, and survival after breast cancer diagnosis. J Clin Oncol. (2005) 23:1370-8. doi: 10.1200/JCO.2005.01.079

6. Caruso C, Balistreri CR, Candore G. The role of adipose tissue and adipokines in obesity-related inflammatory diseases. Mediators Inflamm. (2010) 2010:19. doi: 10.1155/2010/802078

7. Colditz GA, Peterson LL. Obesity and cancer: evidence, impact, and future directions. Clin Chem. (2018) 64:1-9. doi: 10.1373/clinchem.2017.277376

8. Hefetz-Sela S, Scherer PE. Adipocytes: impact on tumor growth and potential sites for therapeutic intervention. Pharmacol Ther. (2013) 138:197-210. doi: 10.1016/j.pharmthera.2013.01.008

9. Pereira LO, Francischi RP De, Lancha AH Jr. Obesidade: hábitos nutricionais, sedentarismo e resistência à insulina. Arq Bras Endocrinol Metabol. (2003) 47:111-27. doi: 10.1590/S0004-27302003000200003

10. Mittwede PN, Clemmer JS, Bergin PF, Xiang L. Obesity and critical illness: insights from animal models. Shock. (2016) 45:349-58. doi: 10.1097/SHK.0000000000000512

11. Heppner GH, Miller FR, Shekhar PM. Nontransgenic models of breast cancer. Breast Cancer Res. (2000) 2:331-4. doi: 10.1186/bcr77

12. Kim E, Choi M-R, Park H, Kim M, Hong J, Lee J-Y, et al. Dietary fat increases solid tumor growth and metastasis of 4T1 murine mammary carcinoma cells and mortality in obesity-resistant BALB/c mice. Breast Cancer Res. (2011) 13:R78. doi: 10.1186/bcr2927

13. Monteiro AC, Leal AC, Gonçalves-Silva T, Mercadante ACT, Kestelman F, Chaves SB, et al. T cells induce pre-metastatic osteolytic disease and help bone metastases establishment in a mouse model of metastatic breast cancer. PLoS ONE. (2013) 8:1-13. doi: 10.1371/journal.pone.0068171

\section{FUNDING}

This work was supported by Minas Gerais State Agency for Research and Development-FAPEMIG, National Council for Scientific and Technological Development (CNPq) and Coordenação de Aperfeiçoamento de Pessoal de Nível Superior (CAPES). GE was funded by grants from National Council for Scientific and Technological Development (CNPq) (grant \# 168524/2017-1). MC-S was funded by grants from Fundação de Amparo à Pesquisa do Estado de São Paulo, FAPESP (grant \# 2017/13686-9).

\section{ACKNOWLEDGMENTS}

The authors would like to thank Dr. Ana Paula Ferreira and Dr. Henrique Couto Teixeira for the assistance provided during the development of this work and to Prof. Dr. Niels Olsen Saraiva Câmara for the critical reading of this manuscript.

14. Burstein MD, Tsimelzon A, Poage GM, Covington KR, Contreras A, Fuqua SAW, et al. Comprehensive genomic analysis identifies novel subtypes and targets of triple-negative breast cancer analysis and interpretation of data: HHS public Access. Clin Cancer Res. (2015) 21:1688-98. doi: 10.1158/1078-0432.CCR-14-0432

15. Taiyun Wei, Simko V, Levy M, Xie Y, Jin Y, Zemla J. Visualization of a Correlation Matrix. (2017) Available online at: https://cran.r-project.org/web/ packages/corrplot/corrplot.pdf (accessed July 24, 2019).

16. Newman AM, Liu CL, Green MR, Gentles AJ, Feng W, Xu Y, et al. Robust enumeration of cell subsets from tissue expression profiles. Nat Methods. (2015) 12:453-7. doi: 10.1038/nmeth.3337

17. Rose DP, Gilhooly EM, Nixon DW. Adverse effects of obesity on breast cancer prognosis, and the biological actions of leptin. Int J Oncol. (2002) 21:1285-92. doi: 10.3892/ijo.21.6.1285

18. Andò $S$, Catalano $S$. The multifactorial role of leptin in driving the breast cancer microenvironment. Nat Rev Endocrinol. (2012) 8:263-75. doi: $10.1038 /$ nrendo.2011.184

19. Gonzalez RR, Cherfils S, Escobar M, Yoo JH, Carino C, Styer AK, et al. Leptin Signaling promotes the growth of mammary tumors and increases the expression of Vascular Endothelial Growth Factor (VEGF) and Its Receptor Type Two (VEGF-R2). J Biol Chem. (2006) 281:26320-8. doi: 10.1074/jbc.M601991200

20. Sun Y, Mao X, Fan C, Liu C, Guo A, Guan S, et al. CXCL12-CXCR4 axis promotes the natural selection of breast cancer cell metastasis. Tumor Biol. (2014) 35:7765-73. doi: 10.1007/s13277-014-1816-1

21. Johnson-Holiday C, Singh R, Johnson EL, Grizzle WE, Lillard JW, Singh S. CCR9-CCL25 interactions promote cisplatin resistance in breast cancer cell through Akt activation in a PI3K-dependent and FAK-independent fashion. World J Surg Oncol. (2011) 9:46. doi: 10.1186/1477-7819-9-46

22. $\mathrm{Hu} \mathrm{X}, \mathrm{Wu} \mathrm{R}$, Jiang $\mathrm{Z}$, Wang $\mathrm{L}$, Chen $\mathrm{P}$, Yang L, et al. Leptin signaling is required for augmented therapeutic properties of mesenchymal stem cells conferred by hypoxia preconditioning. Stem Cell. (2014) 32:2702-13. doi: 10.1002/stem.1784

23. Chu PS, Nakamoto N, Ebinuma H, Usui S, Saeki K, Matsumoto A, et al. C-C motif chemokine receptor 9 positive macrophages activate hepatic stellate cells and promote liver fibrosis in mice. Hepatology. (2013) 58:337-50. doi: 10.1002/hep.26351

24. Matkowski R, Gisterek I, Halon A, Lacko A, Szewczyk K, Staszek U, et al. The prognostic role of tumor-infiltrating CD4 and CD8 T lymphocytes in breast cancer. Anticancer Res. (2009) 29:2445-51. 
25. Mahmoud SMA, Paish EC, Powe DG, Macmillan RD, Grainge MJ, Lee AHS, et al. Tumor-infiltrating CD8 ${ }^{+}$lymphocytes predict clinical outcome in breast cancer. J Clin Oncol. (2011) 29:1949-55. doi: 10.1200/JCO.2010.30.5037

26. Kohrt HE, Nouri N, Nowels K, Johnson D, Holmes S, Lee PP. Profile of immune cells in axillary lymph nodes predicts disease-free survival in breast cancer. PLoS Med. (2005) 2:0904-19. doi: 10.1371/journal.pmed.0020284

27. Grundström S, Dohlsten M, Sundstedt A. IL-2 unresponsiveness in anergic $\mathrm{CD}^{+} \mathrm{T}$ cells is due to defective signaling through the common gamma-chain of the IL-2 receptor. J Immunol. (2000) 164:1175-84. doi: 10.4049/jimmunol.164.3.1175

28. Utting $\mathrm{O}$, Teh SJ, Teh HS. A population of in vivo anergized $\mathrm{T}$ cells with a lower activation threshold for the induction of CD25 exhibit differential requirements in mobilization of intracellular calcium and mitogen-activated protein kinase activation. J Immunol. (2000) 164:2881-9. doi: 10.4049/jimmunol.164.6.2881

29. Chauhan SK, Saban DR, Lee HK, Dana R. Levels of Foxp3 in regulatory $\mathrm{T}$ cells reflect their functional status in transplantation. J Immunol. (2009) 182:148-53. doi: 10.4049/jimmunol.182.1.148

30. Deng L, Zhang H, Luan Y, Zhang J, Xing Q, Dong S, et al. Accumulation of Foxp $3^{+} \mathrm{T}$ regulatory cells in draining lymph nodes correlates with disease progression and immune suppression in colorectal cancer patients. Clin Cancer Res. (2010) 16:4105-12. doi: 10.1158/1078-0432.CCR-101073

31. Zhang Y, Harada A, Bluethmann H, Wang J-B, Nakao S, Mukaida N, et al. Tumor necrosis factor (TNF) is a physiologic regulator of hematopoietic progenitor cells: increase of early hematopoietic progenitor cells in TNF receptor p55-deficient mice in vivo and potent inhibition of progenitor cell proliferation by TNF $\alpha$ in vitro. Blood. (1995) 86:2930-7.

32. Almand B, Resser JR, Lindman B, Nadaf S, Clark JI, Kwon ED, et al. Clinical significance of defective dendritic cell differentiation in cancer. Clin Cancer Res. (2000) 6:1755-66.

33. Liu A, Chen M, Kumar R, Stefanovic-Racic M, O’Doherty RM, Ding $\mathrm{Y}$, et al. Bone marrow lympho-myeloid malfunction in obesity requires precursor cell-autonomous TLR4. Nat Commun. (2018) 9:708. doi: 10.1038/s41467-018-03145-8

34. Sade-Feldman M, Kanterman J, Ish-Shalom E, Elnekave M, Horwitz E, Baniyash M. Tumor necrosis factor- $\alpha$ blocks differentiation and enhances suppressive activity of immature myeloid cells during chronic inflammation. Immunity. (2013) 38:541-54. doi: 10.1016/j.immuni.2013.02.007

35. Kumar V, Patel S, Tcyganov E, Gabrilovich DI. The nature of myeloid-derived suppressor cells in the tumor microenvironment. Trends Immunol. (2016) 37:208-20. doi: 10.1016/j.it.2016.01.004

36. Watanabe S, Deguchi K, Zheng R, Tamai H, Wang LX, Cohen PA. Tumor-induced CD11b Gr-1 myeloid cells suppress $\mathrm{T}$ cell sensitization in tumor-draining lymph nodes. J Immunol. (2008) 181:3291-300 doi: 10.4049/jimmunol.181.5.3291

37. Kerkar SP, Goldszmid RS, Muranski P, Chinnasamy D, Yu Z, Reger RN et al. IL-12 triggers a programmatic change in dysfunctional myeloidderived cells within mouse tumors. J Clin Invest. (2011) 121:4746-57. doi: 10.1172/JCI58814

38. Levine JA, Eberhardt NL, Jensen MD. Role of nonexercise activity thermogenesis in resistance to fat gain in humans. Science. (1999) 283:212-5. doi: $10.1126 /$ science. 283.5399 .212

39. Qian C, Resau JH, Teh BT. Prospects for vasculature reorganization in sentinel lymph nodes. Cell Cycle. (2007) 6:514-7. doi: 10.4161/cc.6. 5.3931

40. Chan ME, Adler BJ, Green DE, Rubin CT. Bone structure and Bcell populations, crippled by obesity, are partially rescued by brief daily exposure to low-magnitude mechanical signals. FASEB J. (2012) 26:4855-63. doi: 10.1096/fj.12-209841

41. Singer K, Delproposto J, Morris DL, Zamarron B, Mergian T, Maley $\mathrm{N}$, et al. Diet-induced obesity promotes myelopoiesis in hematopoietic stem cells. Mol Metab. (2014) 3:664-75. doi: 10.1016/j.molmet.2014. 06.005

42. Yaa S, Maeda K, Malykhin A, Teague-weber BN, Sun X, Farris AD, et al. Interleukin-6 aborts lymphopoiesis and elevates production of myeloid cells in systemic lupus erythematosus - prone B6.Sle1.Yaa animals. Blood. (2009) 113:4534-40. doi: 10.1182/blood-2008-12-192559

43. Rodríguez MDC, Bernad A, Aracil M. Interleukin-6 deficiency affects bone marrow stromal precursors, resulting in defective hematopoietic support. Blood. (2004) 103:3349-54. doi: 10.1182/blood-2003-103438

44. Nam JS, Terabe M, Mamura M, Kang M-J, Chae H, Stuelten C, et al. An anti-TGF- $\beta$ antibody suppresses metastasis via cooperative effects on multiple cell compartments. Cancer Res. (2008) 68:3835-43. doi: 10.1158/0008-5472.CAN-08-0215

Conflict of Interest Statement: The authors declare that the research was conducted in the absence of any commercial or financial relationships that could be construed as a potential conflict of interest.

Copyright (c) 2019 Evangelista, Salvador, Soares, Barros, Xavier, Abdo, Gualberto, Macedo, Clavijo-Salomon and Gameiro. This is an open-access article distributed under the terms of the Creative Commons Attribution License (CC BY). The use, distribution or reproduction in other forums is permitted, provided the original author(s) and the copyright owner(s) are credited and that the original publication in this journal is cited, in accordance with accepted academic practice. No use, distribution or reproduction is permitted which does not comply with these terms. 